\title{
Evaluation of Thermal Stability by Comparison of Potassium Chloride and Potassium/Sodium Formate Fluids
}

\author{
Afshin Davarpanah ${ }^{1 *}$, Mojtaba Zarei $^{2}$ and Ali Razmjoo ${ }^{3}$ \\ ${ }^{1}$ Department of Petroleum Engineering, Science and Research Branch, Islamic Azad University, Tehran, Iran \\ ${ }^{2}$ Department of Chemistry Engineering, Islamic Azad University, Shahr reza, Iran \\ ${ }^{3}$ Department of Energy Systems Engineering, Islamic Azad University, South Tehran Branch, Tehran, Iran
}

\begin{abstract}
Formate drilling fluid is a new type of clean brine drilling fluid system which has been developed from inorganic salt brine drilling fluid system. Currently there are mainly three kinds of format: sodium format, potassium format and cesium format. The laboratory research was carried out to determine the thermal stability of drilling fluid. It was formulated using sodium and potassium format salts, potassium chloride. Formate base mud is solid free system. So, mud cake is thin and resilient, it is conductive to improve cementing quality greatly. Formate base fluids because of their low percent of solid settling. Moreover, the low amount of plastic viscosity these muds help to better hydraulic in the well and better hole cleaning. Hence, drilling penetration rate as an extremely parameter in economic costs are decreased. Environmental pollution of formate salts is dramatically less than recent salts like potassium chloride and sodium chloride. It can be appropriate replacement for these environmental polluted salts.
\end{abstract}

Keywords: Formate drilling fluid; Environmental pollution; Potassium format salts; Thermal stability

Abbrevations: WBM: Water-based mud; FBM: Format base mud; ROP: Rate of penetration; YP: Yield point $\mathrm{lb} / 100 \mathrm{ft}^{2}$; PV: Plastic viscosity cP; Pcf: Pound per cubic feet $\left(\mathrm{lb} / \mathrm{ft}^{3}\right)$.

\section{Introduction}

The new techniques were aimed at creating increasingly extreme well configurations and included long horizontal, extended reach, slim hole, through tubing and coiled tubing drilling. These drilling techniques needed solids-free drilling fluids that could minimize circulating pressure losses and ECD. The format brines provided the ideal basis for such drilling fluids, with the added advantage that they could also function as completion fluids. Further laboratory work over the past 15 years has clearly shown that the format brines in general have very good environmental properties, stabilize shales, inhibit hydrate formation, minimize corrosion, reduce well control problems and minimize formation damage. In short, they appear to be the ideal universal drilling and completion fluids that the oil industry needs in the 21 st century $[1,2]$.

\section{Shale oil reservoirs}

Hydrocarbon accumulations in petroleum reservoirs around the world migrated from very fine-grained, dark-gray or black organicrich sedimentary source rocks, referred to as organic-rich shales. For decades, organic-rich shale formations have been regarded as source rocks from which hydrocarbons originated and migrated into sandstone and limestone of various reservoir qualities. Oil- and gas-prone shales form when massive amounts of organic debris deposition occur in swamps, lakes, marine environments, followed by rapid burial without decay [3]. Subsequently, over geologic time, these organic constituents convert into hydrocarbons under the effect of temperature and pressure changes in the subsurface due to burial. Thus, these organic-rich shales undergo the necessary geologic processes from digenesis to cat agenesis to convert dead organic contents into useful hydrocarbons [4].

Shale oil and conventional oil reservoirs require different development strategies for economic oil recovery. Low permeability shale reservoirs require extensive hydraulic fracture stimulation treatments at the onset of economic oil recovery [5]. On the other hand, conventional reservoirs have relatively good permeability, and therefore produce at economic rates without hydraulic fractures. Understanding petro physical and geo- mechanical properties is essential for optimum stimulation treatment of shale reservoirs.

\section{Formate fluids}

Format drilling fluid is a new type of clean brine drilling fluid system which has been developed from inorganic salt brine drilling fluid system. Currently there are mainly three kinds of format: sodium format, potassium format and cesium format. Compared with conventional drilling fluid, format drilling fluid is characterized by no bentonite slurry. It is the theoretical foundation that format drilling fluid can achieve strong inhibitory, and it is also the key to being better than conventional water base drilling fluid. Wang Yong sheng has studied the application effect of the format drilling fluid in Yingtai gas field in 2012. And this drilling fluid system has helped to protect the reservoir and save the exploration cost. Based on the previous research, this paper is studied for some new findings and applications [6].

Format has the characteristics of high solubility, high density, high $\mathrm{pH}$ value, low crystallization point. With the increase of alkali metal atomic weight, saturation concentration, saturation density and $\mathrm{pH}$ value become higher, and crystallization point becomes lower.

Through indoor study, the following features of for- mate have been found:

*Corresponding author: Afshin Davarpanah, Department of Petroleum Engineering, Science and Research Branch, Islamic Azad University, Tehran, Iran, Tel: +989178546466; E-mail: afshindpe@gmail.com

Received December 03, 2016; Accepted December 22, 2016; Published January 06, 2017

Citation: Davarpanah A, Zarei M, Razmjoo A (2017) Evaluation of Thermal Stability by Comparison of Potassium Chloride and Potassium/Sodium Formate Fluids. Environ Anal Toxicol 7: 426. doi: 10.4172/2161-0525.1000426

Copyright: (c) 2017 Davarpanah A, et al. This is an open-access article distributed under the terms of the Creative Commons Attribution License, which permits unrestricted use, distribution, and reproduction in any medium, provided the original author and source are credited. 
Citation: Davarpanah A, Zarei M, Razmjoo A (2017) Evaluation of Thermal Stability by Comparison of Potassium Chloride and Potassium/Sodium Formate Fluids. J Environ Anal Toxicol 7: 426. doi: 10.4172/2161-0525.1000426

Page 2 of 4

(1) There is the function of stabilizing shale. Shale is equivalent to the selective semi-permeable membrane in the non-fractured low permeability shale formation $\left(\mathrm{K} \leq 10 \times 10^{-3} \mu \mathrm{m}^{2}\right)$. In the high concentration brine, due to the low water activity, the osmotic pressure can promote the shale pore water reflux. This reflux will make formation stress and effective stress of near wellbore zone increase to stabilize borehole wall.

(2) Format has a good compatibility with the oilfield commonly used polymer, and can slow the speed of hydrolysis and oxidation degradation of many thickeners and filtrate reducers under high temperature and pressure [7-12].

\section{Field Evaluation}

The vertical well to be drilled was an exploration well that could provide information on potential reservoirs and lithological information of the field. No offset data was available on the well and the nearest well information was $80 \mathrm{~km}$ away. Geologist forecast from this well required drilling through reactive shales in member (A). Table 1 lists the interval parameters for drilling.

The objective was to drill a $81 / 2$-in. hole section from $10900 \mathrm{ft}$ through member (A), to the casing point at a measured depth (MD) of $12500 \mathrm{ft}$. A 7-in. casing string was then to be run and cemented. The FBM optimized for member (A) was expected to provide maximum shale stabilization and inhibition to achieve maximum ROP without any incidents such as tight hole, pipe stuck and hole filling.

\section{Laboratory Procedure}

In this test, rheological properties and potassium/sodium formate fluid reduction before and after the applying the temperature to the potassium chloride (KCL) are being compared. These two fluid formulations regarding to the used polymers and other component are the same and the only difference is in the type of using salt. Figures 1-3 show the rheological properties of formate fluid and potassium chloride samples before and after applying temperature up to $250^{\circ} \mathrm{F}$ during the time period of 16 hours.

The salt mud was then displaced with the FBM with a density of 80 pcf per the mud program. After the FBM was circulated and conditioned for 5 hours as bypass. Drilling was performed without any problem with formation loss 1-3 BPH until reaching MD $11270 \mathrm{ft}$, where mud making is no possible because of shortage format salts. To control this problem, pull out of string $(\mathrm{POOH})$ was done and is decided to change mud formulation system with oil based mud for continuing drill the hole. Drilling time of interval from 10800 to $11270 \mathrm{ft}$ that using Format based mud was about 70 hours.

As it can be seen in the Figure 1, the amount of apparent viscosity in the formate fluids is more than potassium chloride fluid. Noticeable parameter is that the amount of apparent viscosity reduction after

\begin{tabular}{|c|c|}
\hline \multicolumn{2}{|c|}{ Interval parameters } \\
\hline Formation Type & Member A compose of shale \\
\hline Thickness interval depth & 400 feet \\
\hline Interval Hole size & $81 / 2$ inches \\
\hline Fluid Type & Format based mud \\
\hline Bit type & Mill Tooth bit \\
\hline Nozzle size & $3 \times 16 / 32$ inches \\
\hline String Rotation speed (rpm) & $100-130 \mathrm{rpm}$ \\
\hline Weight on Bit (WOB) & $20-25 \mathrm{klb}$ \\
\hline
\end{tabular}

Table 1: Interval parameters for drilling.

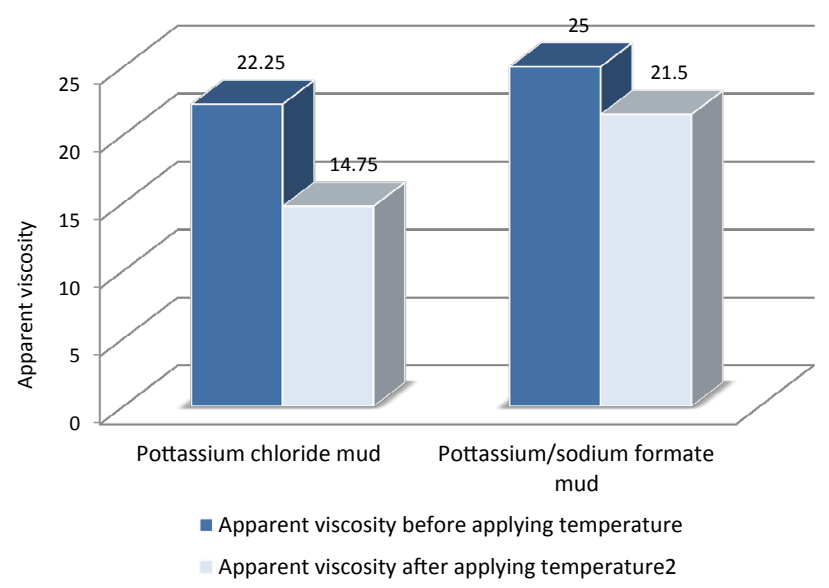

Figure 1: Comparison of apparent viscosity between formate fluid and potassium chloride before and after applying temperature.

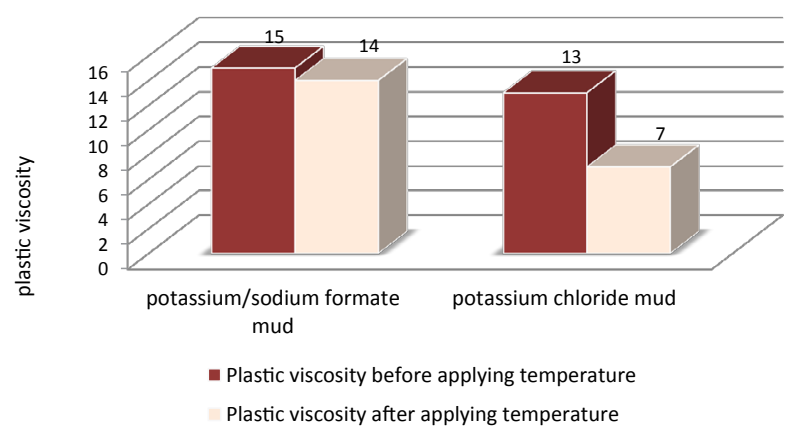

Figure 2: Comparison of plastic viscosity between formate fluid and potassium chloride before and after applying temperature.

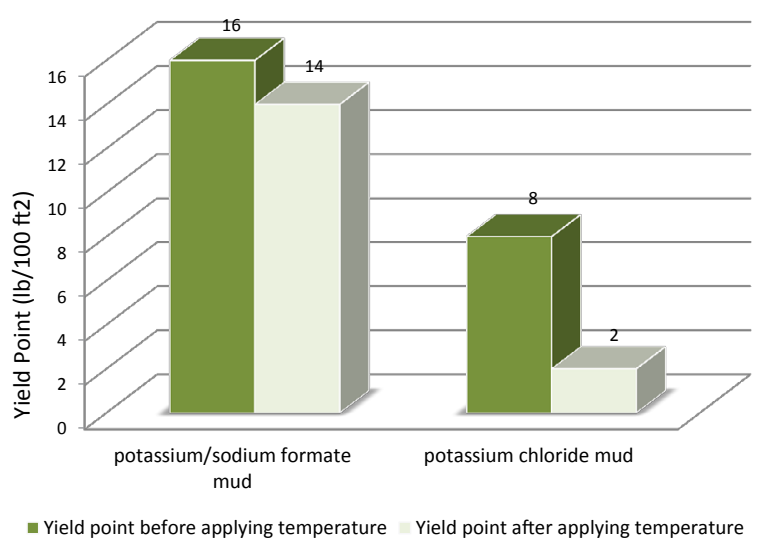

Figure 3: Comparison of Yield point between formate fluid and potassium chloride before and after applying temperature.

applying temperature in the formate fluid is less than potassium chloride fluid. In the other word, apparent viscosity of potassium chloride fluid after applying temperature has been reduced more. The apparent viscosity of mud systems with formate salts was maintained (50\% of its original properties are retained), but in these cases without formate salts, the apparent viscosity was not maintained. It was observed that the desired rheological properties are obtained by using formate salt to 
Citation: Davarpanah A, Zarei M, Razmjoo A (2017) Evaluation of Thermal Stability by Comparison of Potassium Chloride and Potassium/Sodium Formate Fluids. J Environ Anal Toxicol 7: 426. doi: 10.4172/2161-0525.1000426

Page 3 of 4

avoid of some problems in drilling operations such as filatures in rig pumps.

The thermal stability of mud systems were examined in the presence of potassium and sodium formate brines at aging condition. Figure 2 show the plastic viscosity of formate fluid and potassium chloride before and after applying temperature. As it can be seen in the Figure 2, the amount of plastic viscosity before applying temperature are the same. Even though, after applying temperature plastic viscosity of potassium chloride has a large reduction. Moreover in the formate fluid the loss of plastic viscosity is negligible.

Figure 3 show the yield point of formate fluid and potassium chloride before and after applying temperature. As it can be seen in the Figure 3, the amount of yield point after applying temperature has a noticeable reduction.

Figure 4 show the reduction level of formate fluid and potassium chloride before and after applying temperature. As it can be seen in the Figure 4, in spite of simultaneously formulation in terms of type and the amount of polymer that is used in the fluids combination, reduction level of formate fluid is less than potassium chloride.

Furthermore, it can be seen that amount of reduction level in potassium chloride fluid after applying temperature has increased dramatically. Although in formate fluid reduction level after applying temperature didn't have a shoot up and it relatively reached plateau. Thereby, it can be concluded that formate salts caused to increase the polymers and starch thermal stability and rose its efficiency in the high temperatures.

Figure 5 show the shale recovery for potassium/sodium formate fluid and potassium chloride fluid. As it can be seen in the Figure 5 the amount of shale recovery in the formate fluids are more than potassium chloride fluids. Therefore, it can be concluded that formate salts specially potassium formate have better shale stability than the other salts. In addition, environmental pollution of formate salts is dramatically less than recent salts like potassium chloride and sodium chloride. It can be appropriate replacement for these environmental polluted salts.

The possibility of using formate salts for the formulation of drilling mud had been investigated in experimental tests and field application. From the experimental results, the thermal stability of polymers in water based drilling fluid under aging condition was increased and the shale inhibition performance of drilling fluid was so close to oil-based drilling fluid that could effectively solve the problem of mud-making, bit balling, cuttings bed, tripping resistance, slow ROP and other issues.

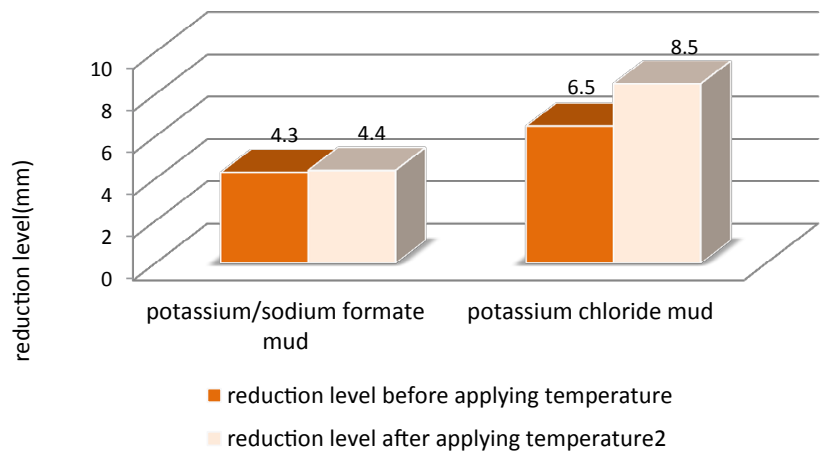

Figure 4: Comparison of Reduction level between formate fluid and potassium chloride before and after applying temperature.

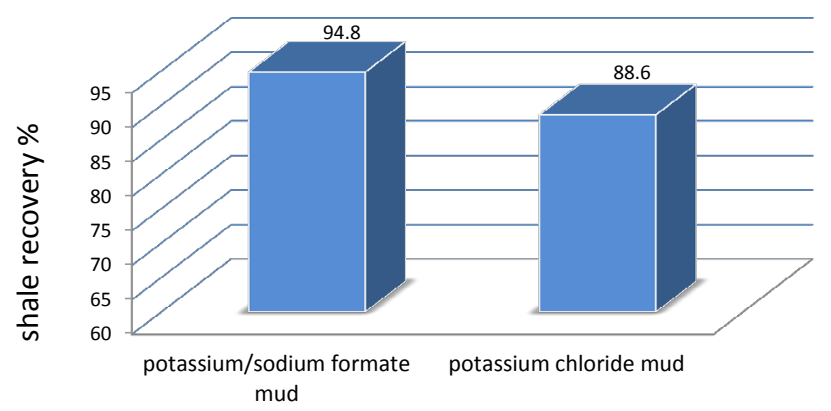

Figure 5: Comparison of shale recovery between formate fluid and potassium chloride 4-Field Evaluation.

The vertical well to be drilled was an exploration well that could provide information on potential reservoirs and lithological information of the field. No offset data was available on the well and the nearest well information was $80 \mathrm{~km}$ away. Geologist forecast from this well required drilling through reactive shales in member (A). Table 1 lists the interval parameters for drilling.

The objective was to drill a 8 1/2-in. hole section from $10900 \mathrm{ft}$ through member (A), to the casing point at a measured depth (MD) of $12500 \mathrm{ft}$. A 7-in. casing string was then to be run and cemented. The FBM optimized for member (A) was expected to provide maximum shale stabilization and inhibition to achieve maximum ROP without any incidents such as tight hole, pipe stuck and hole filling.

\section{Results and Conclusions}

\section{Results}

- Apparent viscosity of potassium chloride fluid after applying temperature has been reduced more.

- After applying temperature plastic viscosity of potassium chloride has a large reduction. Moreover in the formate fluid the loss of plastic viscosity is negligible.

- The amount of yield point after applying temperature has a noticeable reduction.

- The amount of reduction level in potassium chloride fluid after applying temperature has increased dramatically. Although in formate fluid reduction level after applying temperature didn't have a shoot up and it relatively reached plateau.

- The amount of shale recovery in the formate fluids are more than potassium chloride fluids.

\section{Conclusions}

- The use of a format based drill fluid instead of salt based fluid allowed for beneficial modifications to the drilling practice with positive results:

(i) It exhibited superior hole-cleaning qualities throughout the interval and no significant drag was observed during drilling. It decreased the need for pills to assist with hole cleaning.

(ii) Flow rates could be increased from typical $350-400 \mathrm{gal} / \mathrm{min}$ to $450 \mathrm{gal} / \mathrm{min}$ because of the reduced frictional pressure losses of the format system. 
Citation: Davarpanah A, Zarei M, Razmjoo A (2017) Evaluation of Thermal Stability by Comparison of Potassium Chloride and Potassium/Sodium Formate Fluids. J Environ Anal Toxicol 7: 426. doi: 10.4172/2161-0525.1000426

Page 4 of 4

(iii) It reduced the need for back reaming out of the hole for hole cleaning.

(iv) It achieved faster than expected penetration rates in total formation drilling time was achieved.

- It can be concluded that formate salts caused to increase the polymers and starch thermal stability and rose its efficiency in the high temperatures.

- Environmental pollution of formate salts is dramatically less than recent salts like potassium chloride and sodium chloride. It can be appropriate replacement for these environmental polluted salts.

\section{References}

1. Downs JD, Killie S, Whale GF (1994) Development of environmentally benign formate-based drilling and completion fluids. InSPE Health, Safety and Environment in Oil and Gas Exploration and Production Conference. Society of Petroleum Engineers.

2. Chenevert ME (1998) Drilling Fluid Optimization in Shales: Swelling Pressure and Compressive Strength of Shale: Topical Report. Gas Research Institute.

3. Passey QR, Bohacs K, Esch WL, Klimentidis R, Sinha S (2010) From oilprone source rock to gas-producing shale reservoir-geologic and petrophysical characterization of unconventional shale gas reservoirs. In: International oil and gas conference and exhibition in China. Society of Petroleum Engineers.

4. Sondhi N (2011) Petrophysical Characterization of the Eagle Ford Shale.
Norman, Oklahoma: Mewbourne School of Petroleum and Geological Engineering.

5. Miskimins JL (2008) Design and Life Cycle Considerations for Unconventional Reservoir Wells. Paper SPE 114170 presented at the SPE Unconventional Reservoirs Conference, Keystone, Colorado, USA, 10-12 February.

6. Gao P, Yin D (2006) Simulation study on the conditions of converting injection wells to production wells in low permeability reservoirs. Journal of Daqing Petroleum Institute 6: 12-22.

7. Moake GL (2012) Formate mud effects on density logs. In: SPWLA $53^{\text {rd }}$ Annual Logging Symposium 2012 Jun 16. Society of Petrophysicists and Well-Log Analysts.

8. Hands N, Francis P, Whittle A, Rajasingam D (1998) Optimizing Inflow Performance of a Long Multi-Lateral Offshore Well in Low Permeability, Gas Bearing Sandstone: K14-FB 102 Case Study. SPE 50394, SPE International Conference on Horizontal Well Technology, Calgary.

9. Rock to Gas-Producing Shale Reservoir-Geologic and Petrophysical Characterization of Unconventional Shale Gas Reservoirs. SPE 131350, pp: 1-29.

10. Martin R, Baihly J, Malpani R, Lindsay G, Atwood KW, et al. (2011) Understanding Production from Eagle Ford-Austin Chalk System. SPE 145117, pp: $1-28$.

11. Chaudhary AS, Ehlig-Economides C, Wattenbarger R (2011) Shale Oil Production Performance from a Stimulated Reservoir Volume. SPE 147596 pp: 1-21.

12. Medeiros F, Ozkan E, Kazemi $H$ (2008) Productivity and Drainage Area of Fractured Horizontal Wells in Tight Gas Reservoirs. SPE 108110, pp: 1-10. 